\title{
Perbedaan Respon Hemodinamik dengan Penambahan Blok Scalp Levobupivakain pada Operasi Kraniotomi
}

\author{
Arya Justisia Sani, Justisia Sani Arya, Ardhana Tri Arianto, Muhammad Husni Thamrin \\ Departemen Anestesiologi dan Terapi Intensif Fakultas Kedokteran Sebelas Maret-RSUD Dr. Moewradi Surakarta
}

\begin{abstract}
Abstrak
Latar Belakang dan Tujuan: Peningkatan respon hemodinamik yang disebabkan oleh nyeri dapat menyebabkan peningkatan aliran darah otak dan tekanan intrakranial. Blok scalp pada kraniotomi menumpulkan respon hemodinamik karena rangsangan nyeri serta mengurangi penambahan analgesi lain. Penelitian ini bertujuan untuk mengetahui efektifitas blok scalp sebagai analgetik pada kraniotomi.

Subjek dan Metode: Penelitian ini menggunakan uji klinik acak tersamar ganda pada 36 pasien dengan status fisik ASA 1-3 dilakukan operasi kraniotomi eksisi dan memenuhi kriteria inklusi. Sampel dibagi menjadi kelompok I (dengan blok scalp) dan kelompok II (tanpa blok scalp). Blok dilakukan sesaat setelah induksi anestesi. Digunakan levobupivakain 0,375\% sebanyak $3 \mathrm{ml}$ tiap insersi, pada masing-masing saraf. Tekanan darah, tekanan arteri ratarata, detak jantung sebelum intubasi dan setelah intubasi, pemasangan pin, insisi kulit dan insisi duramater serta total kebutuhan fentanyl tambahan dicatat. Data yang diperoleh dianalisis dengan program komputer SPSS versi 17 lalu diuji menggunakan uji Kruskal-Wallis atau One-way ANOVA. Batas kemaknaan yang diambil adalah p $<0,05$. Hasil: Selama kraniotomi, detak jantung, tekanan darah, tekanan arteri rata-rata secara signifikan lebih tinggi pada pasien tanpa blok scalp terutama pada saat pemasangan pin. Hasil uji statistik menunjukkan perbedaan signifikan, penambahan fentanyl pada pasien dengan blok scalp lebih sedikit dibandingkan tanpa blok scalp, $\mathrm{p}=0,000(\mathrm{p}<0,05)$. Simpulan: Blok scalp levobupivakain efektif dalam menurunkan respon hemodinamik terutama pada saat pemasangan pin. Pasien kraniotomi dengan blok scalp membutuhkan penambahan fentanyl lebih sedikit.
\end{abstract}

Kata kunci: Blok scalp; fentanyl; kraniotomi; levobupivakain

JNI 2020; 9 (1): 8-15

\section{Differences on Hemodynamic Response with Levobupivacaine Scalp Block in Craniotomy Surgery}

\begin{abstract}
Background and Objective: Increased hemodynamic response caused by pain can lead to increased cerebral blood flow and intracranial pressure. Scalp block in craniotomy blunts hemodynamic response due to pain and reduce other analgesics addition. This study aims to determine effectiveness of scalp blocks as analgesic in craniotomy. Subject and Method: This study used a double-blind randomized clinical trial in 36 patients with physical status ASA 1-3 who underwent craniotomy and met inclusion criteria. Samples were divided into group I (with scalp block) and group II (without scalp block). Scalp Block was performed right after anesthesia induction. Using levobupivacaine $0.375 \% 3 \mathrm{ml}$ for each insertion. Blood pressure, mean arterial pressure, heart rate before and after intubation, during pin placement, skin incision and duramater incision and total need for additional fentanyl were recorded. SPSS version 17 was used and data were analysed using Kruskal-Wallis or One-way ANOVA. Statistical significance was accepted at $\mathrm{p}<0.05$.

Result: During craniotomy, heart rate, blood pressure, mean arterial pressure were significantly higher in patients without scalp block especially during pin placement. Statistical test showed significant difference, additional fentanyl in patients with scalp blocks was lesser, $p=0.000(p<0.05)$.

Conclusion: Levobupivacaine scalp block was effective to blunt hemodynamic response especially during pin placement. Scalp block also decreased additional fentanyl in craniotomy.
\end{abstract}

Key words: Craniotomy; fentanyl; levobupivacaine; scalp block

JNI 2020; 9 (1): 8-15 


\section{Pendahuluan}

Pada pasien yang sebelumnya tekanan darah normal lebih disukai sistolik sekitar 90-100 $\mathrm{mmHg}$ dan aliran darah otak dipertahankan konstan pada tekanan arteri rata-rata (Mean Arterial Pressure/MAP) 50-150 mmHg. Pada saat laringoskopi-intubasi, pemasangan pin, sayatan kulit, membor tulang kepala atau saat ekstubasi dapat terjadi kenaikan tekanan darah $(>20 \%$ base line) dan tekanan arteri rata-rata $(>150 \mathrm{mmHg})$ dapat menyebabkan terjadinya peningkatan aliran darah otak, volume darah otak, tekanan intrakranial, edema otak, hiperemia, dan perdarahan otak. ${ }^{1-3}$

Peningkatan terus-menerus pada tekanan intrakranial dapat menyebabkan herniasi pada otak yang dapat menekan pusat fungsi vital yang dihubungkan dengan gejala bradikardia, hipertensi dan pernapasan yang irreguler diikuti apnea. ${ }^{4}$ Walaupun sudah banyak teknik anestesi yang tersedia, resiko terjadinya ketidakstabilan dari hemodinamik di awal prosedur bedah saraf pada saat pemasangan pin, kraniotomi dan insisi dura masih sangat tinggi. ${ }^{5}$ Perubahan pada tekanan darah dan detak jantung dapat mempengaruhi sistem kardiovaskular dan perfusi serebral pasien. Salah satu solusinya adalah menggunakan opioid seperti fentanyl dosis tinggi yang dapat memberikan analgesia yang cukup tetapi dapat memberikan efek-efek yang lain seperti telat pulih sadar dan tidak dapat dilakukannya evaluasi neurologis dengan segera. ${ }^{6,7}$

Dengan melakukan blok saraf-saraf sensoris yang menginervasi kranial dapat membantu menumpulkan respon hemodinamik karena rangsangan nyeri. Anestesi lokal durasi panjang seperti levobupivakain mempunyai toksisitas kardiovaskular dan sistem saraf pusat lebih rendah daripada bupivakain sehingga penggunaannya pada blok scalp mempunyai keuntungannya tersendiri. Dari penelusuran penulis, terdapat beberapa penelitian yang membuktikan blok scalp efektif untuk mengurangi nyeri maupun respon hemodinamik selama operasi kraniotomi. Satu penelitian melakukan block scalp menggunakan ropivakain $0,75 \%$ dan nyeri dinilai pada saat opersi dan post operasi dan didapatkan pada yang menggunakan ropivakain mempunyai skor nyeri dan respon hemodinamik yang lebih rendah dibanding yang hanya menggunakan salin. Penelitian lain yang serupa pada pasien yang menjalani kraniotomi supratentorial dengan menggunakan bupivakain dan plasebo, penelitian tersebut berkesimpulan bahwa pasien yang tidak dilakukan blok scalp bupivakain mempunyai skor nyeri post operatif yang lebih besar. ${ }^{8-10}$ Oleh karena itu penelitian ini ingin juga membuktikan apakah blok scalp menggunakan levobupivakain dapat secara efektif digunakan untuk menjaga kestabilan hemodinamik dan mengurangi kebutuhan opioid pada operasi kraniotomi di RSUD Dr. Moewardi, Surakarta.

\section{Subjek dan Metode}

Penelitian ini menggunakan desain uji klinis acak tersamar ganda dan dilakukan di Instalasi Bedah Sentral Rumah Sakit Dr. Moewardi Surakarta dengan mengumpulkan data pasien pasien yang menjalani operasi kraniotomi eksisi tumor sejak 2018 hingga jumlah 36 sampel. Kriteria inklusi: pasien berusia 18-65 tahun, menjalani operasi kraniotomi eksisi tumor, status fisik ASA 1-3. Kriteria eksklusi: terdapat kontra-indikasi absolut untuk anestesi regional, alergi terhadap fentanyl. Kriteria putus uji, perubahan tindakan operasi dari operator, timbul hipersensitivitas (alergi) terhadap preparat anestesi. Penelitian dilakukan setelah mendapat informed consent dan disetujui oleh komisi etik penelitian bidang kesehatan Fakultas Kedokteran Universitas Sebelas Maret

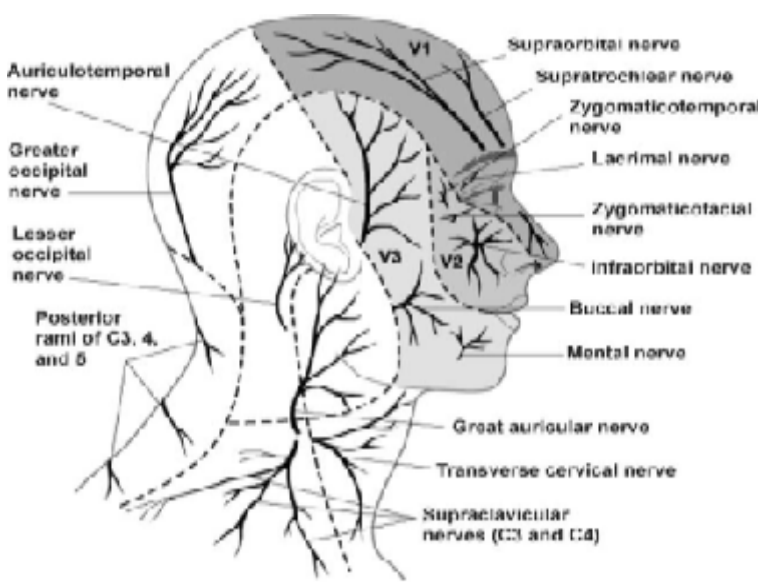

Gambar 1. Inervasi Scalp dan Wajah. Sumber ${ }^{9}$ 
Surakarta/RSUD Dr. Moewardi Surakarta. Pasien yang menyetujui mengikuti penelitian ini kemudian dicatat. Pencatatan meliputi: umur, jenis kelamin, diagnosis penyakit dasar, tanggal dilakukan operasi. Peneliti meminta bantuan relawan untuk melakukan randomisasi dalam menentukan pasien yang mendapat blok scalp levobupivakain $0,375 \%$ (kelompok I) maupun kelompok tanpa perlakuan blok scalp (Kelompok II). Operasi dilakukan dengan persiapan alat-alat dan obat-obatan untuk teknik anestesi umum, intubasi oral dan respirasi kontrol secara standar. Di ruang operasi pasien diberikan premedikasi fentanyl $2 \mathrm{mcg} / \mathrm{kg}$ intravena. Induksi dengan menggunakan propofol $1-2 \mathrm{mg} / \mathrm{kg}$ titrasi sampai dengan pasien tertidur. Setelah jalan napas dan ventilasi terkuasai diberikan pelumpuh otot vecuronium $0,1 \mathrm{mg} / \mathrm{kgbb}$. Intubasi dengan ukuran ETT yang sesuai dan kemudian anestesi dipertahankan dengan sevofluran 2 vol\% dan kombinasi oksigen-udara dengan fraksi 50\% serta fentanyl $1 \mathrm{mcg} / \mathrm{kg}$ berat badan/jam. Bolus fentanyl 25-50 mcg diberikan bila terjadi peningkatan denyut jantung atau tekanan darah lebih dari $20 \%$ nilai basal. Pelumpuh otot vecuronium 1-2 $\mathrm{mcg} / \mathrm{kg}$ berat badan/menit dengan menggunakan syringe pump selama operasi. Sebelum insisi dari operator (dokter bedah) menambahkan infiltrasi lokal pada daerah insisi dengan menggunakan lidokain 2\% dan adrenalin 1:100.000.

Setelah tindakan asepsis-antisepsis, spuit 10 $\mathrm{ml}$ dengan jarum no $23 \mathrm{G}$, diinjeksikan secara subkutan. Dilakukan blok scalp levobupivakain $0,375 \%$ oleh tim anestesi yang bertugas di kamar operasi bedah saraf. Blok dilakukan sesaat setelah induksi anestesi. Obat anestesi lokal yang digunakan adalah levobupivakain $0,375 \%$ sebanyak $3 \mathrm{ml}$ masing masing insersi. Saraf supraorbital: jarum disuntikkan sepanjang batas orbital perpendikular dengan kulit, kirakira $1 \mathrm{~cm}$ medial ke foramen supraorbital, saraf supratrochlear: infiltrasi paralel ke saraf supraorbital (medialnya), saraf aurikulotemporal: infiltrasi sepanjang prosesus zygomatikus dengan injeksi $1-1,5 \mathrm{~cm}$ anterior setinggi tragus, saraf zygomatikotemporal: infiltrasi pada batas supraorbital ke bagian posterior dari lengkungan zygomatikus, saraf oksipital besar: infiltrasi sekitar setengah jalan antara protuberans oksipital dan prosesus mastoideus, $2,5 \mathrm{~cm}$ ke lateral garis nukal median, saraf oksipital kecil: infiltrasi sepanjang medial superior, $2,5 \mathrm{~cm}$ lateral dari oksipital besar. Blok juga dilakukan untuk daerah kepala sebelahnya (bilateral). Tekanan darah, tekanan arteri rata-rata, detak jantung sebelum intubasi dan setelah intubasi, pemasangan pin, insisi kulit dan insisi duramater serta total kebutuhan fentanyl tambahan dicatat. Selama operasi pasien diawasi dan dicatat tekanan darah, tekanan arteri rerata dan denyut jantung (terutama pada saat sesaat setelah intubasi, pemasangan pin, insisi kulit, dan insisi duramater), serta durasi operasi dan jumlah opioid yang diberikan. Masing-masing kelompok dinilai respon hemodinamiknya. Kelompok blok scalp dengan levobupivakain $0,375 \%$ dinilai hematom, infeksi dan cedera saraf. Untuk kelompok fentanyl dinilai reaksi alergi atau pruritus. Pada penelitian ini tidak dilakukan pengukuran IoC (Index of Consciousness) karena tidak tersedianya alat serta lokasi pemasangan alat merupakan daerah operasi. Variabel data demografi akan dicari nilai reratanya dan perbandingan variabel pada masing - masing kelompok akan diuji dengan uji Kruskal Wallis untuk data nominal dan ordinal. Sedangkan untuk data numerik menggunakan uji One-way ANOVA. Variabel data perbedaan respon hemodinamik masing-masing kelompok akan diuji dengan One-way ANOVA bila data terdistribusi normal atau dengan uji Kruskal Wallis jika data terdistribusi tidak normal. Batas kemaknaan yang diambil adalah $\mathrm{p}<0,05$.

\section{Hasil}

Penelitian ini dilakukan pada 36 pasien yang menjalani operasi kraniotomi eksisi tumor di RS Dr. Moewardi Surakarta dibagi menjadi 18 subjek kelompok I (dengan penambahan blok scalp levobupivakain) dan 18 subjek kelompok II (tanpa penambahan blok scalp levobupivakain). Respon hemodinamik dalam penelitian ini meliputi tekanan darah (sistolik dan diastolik), MAP dan laju nadi.

Berdasarkan tabel 6 dan gambar 7. diketahui bahwa efek samping yang terjadiadalah hipertensi, 
Tabel 1. Perbedaan tekanan darah sistolik antara kelompok yang diberikan terapi tambahan blok scalp (kelompok I) dengan pasien tanpa terapi tambahan blok scalp (kelompok II)

\begin{tabular}{llll}
\hline Tekanan Darah Sistolik & \multicolumn{2}{c}{ Perlakuan } & P \\
\cline { 2 - 3 } & $\begin{array}{l}\text { Kelompok I } \\
(\mathrm{n}=18)\end{array}$ & $\begin{array}{l}\text { Kelompok II } \\
(\mathrm{n}=18)\end{array}$ & \\
\hline Setelah Intubasi & $133,89 \pm 10,23$ & $137,17 \pm 6,99$ & 0,3852 \\
Pemasangan Pin & $137,94 \pm 11,76$ & $157,50 \pm 17,45$ & 0,0002 \\
Insisi kulit & $130,17 \pm 8,87$ & $145,78 \pm 12,82$ & 0,0002 \\
Insisi Durameter & $124,39 \pm 9,09$ & $139,50 \pm 12,00$ & 0,0001 \\
\hline${\text { Ket }: \text { uji independent } \text { test }^{1} \text {; }}^{\text {uji }}$ mann whitney $^{2}$ & &
\end{tabular}

Ket : uji independent $t$ test $^{1}$; uji mann whitney ${ }^{2}$

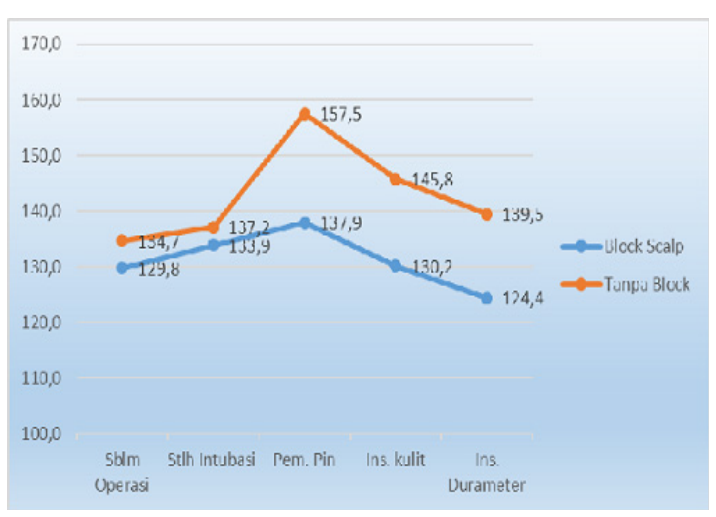

Gambar 2. Diagram Garis Perbandingan

Perubahan Tekanan Darah Sistolik antara Kelompok Blok Scalp dengan Kelompok Tanpa Blok

Pemasangan pin pasien pada kelompok I dengan tekanan darah sistolik rata-rata $137,94 \pm 11,76$ dan pada kelompok II dengan tekanan darah sistolik rata-rata $157,50 \pm 17,45$. Hasil uji statistik didapatkan nilai $\mathrm{p}=0,000(\mathrm{p}<0,05)$ yang berarti terdapat perbedaan yang signifikan tekanan darah sistolik pasien antara kelompok I dan kelompok II saat pemasangan pin.

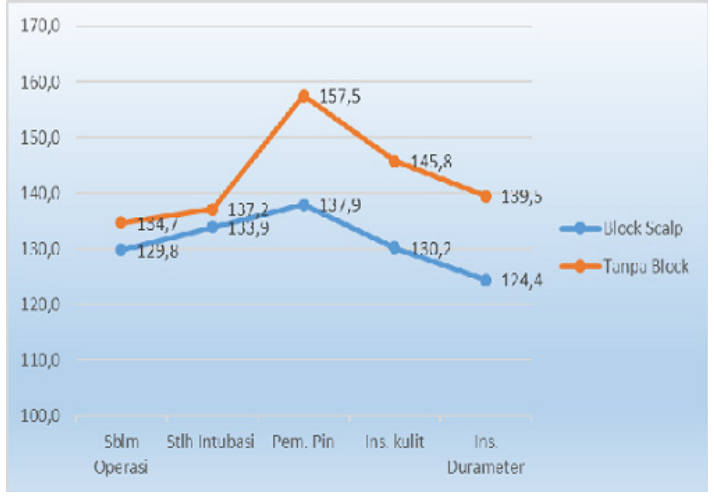

Gambar 3. Diagram Garis Perbandingan Perubahan Tekanan Darah Diastolik antara Kelompok Block Scalp dengan Kelompok Tanpa Blok.

Waktu pemasangan pin pasien pada kelompok I dengan tekanan darah diastolik rata-rata $80,39 \pm 5,56$ dan pada kelompok II dengan tekanan darah diastolik rata-rata $88,22 \pm 8,76$. Hasil uji statistik didapatkan nilai $\mathrm{p}=0,003(\mathrm{p}<0,05)$ yang berarti bahwa terdapat perbedaan yang signifikan tekanan darah diastolik pasien antara kelompok I dan kelompok II waktu pemasangan pin

Tabel 2. Perbedaan tekanan darah diastolik antara kelompok yang diberikan terapi tambahan blok scalp (kelompok I) dengan pasien tanpa terapi tambahan blok scalp (kelompok II)

\begin{tabular}{lccc}
\hline Tekanan Darah Sistolik & \multicolumn{2}{c}{ Perlakuan } & P \\
\cline { 2 - 3 } & $\begin{array}{c}\text { Kelompok I } \\
(\mathrm{n}=18)\end{array}$ & $\begin{array}{c}\text { Kelompok II } \\
(\mathrm{n}=18)\end{array}$ & \\
\hline Setelah Intubasi & $78,22+5,90$ & $79,50+4,58$ & $0,359^{2}$ \\
Pemasangan Pin & $80,39+5,56$ & $88,22+8,76$ & 0,0031 \\
Insisi kulit & $77,94+2,96$ & $79,67+2,93$ & $0,190^{2}$ \\
Insisi Durameter & $78,33+4,77$ & $81,89+5,00$ & $0,149^{2}$ \\
\hline
\end{tabular}


Tabel 3. Perbedaan MAP antara kelompok yang diberikan terapi tambahan blok scalp (kelompok I) dengan pasien tanpa terapi tambahan blok scalp (kelompok II)

\begin{tabular}{llll}
\hline MAP & \multicolumn{2}{c}{ Perlakuan } & P \\
\cline { 2 - 3 } & $\begin{array}{c}\text { Kelompok I } \\
(\mathrm{n}=18)\end{array}$ & $\begin{array}{c}\text { Kelompok II } \\
(\mathrm{n}=18)\end{array}$ & \\
\hline Setelah Intubasi & $95,78 \pm 4,83$ & $98,39 \pm 3,70$ & $0,077^{1}$ \\
Pemasangan Pin & $99,39 \pm 6,93$ & $110,94 \pm 10,55$ & $0,000^{2}$ \\
Insisi kulit & $94,89 \pm 3,79$ & $101,39 \pm 4,90$ & $0,000^{1}$ \\
Insisi Durameter & $93,50 \pm 4,94$ & $100,72 \pm 6,34$ & $0,000^{2}$ \\
\hline
\end{tabular}

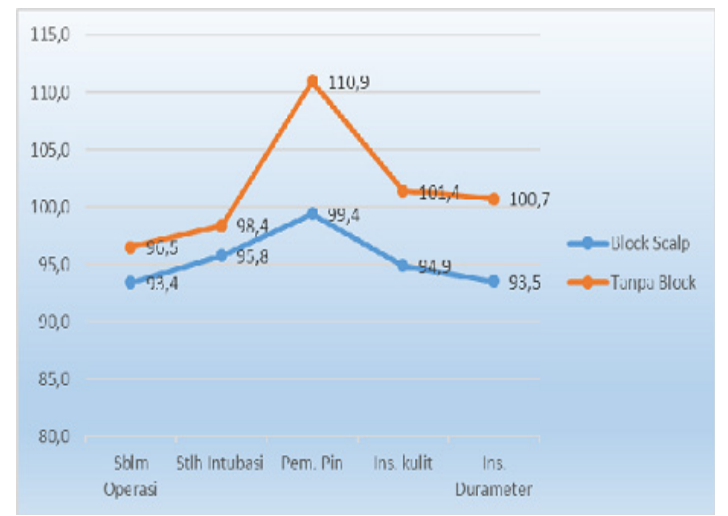

Gambar 4. Diagram Garis Perbandingan Perubahan MAP antara Kelompok Blok Scalp dengan Kelompok Tanpa Blok.

Waktu pemasangan pin pasien pada kelompok I dengan MAP rata-rata 99,39+6,93 dan pada kelompok II dengan MAP rata-rata 110,94 $\pm 10,55$. Hasil uji statistik didapatkan nilai $\mathrm{p}=0,000$ $(\mathrm{p}<0,05)$ yang berarti bahwa terdapat perbedaan yang signifikan MAP pasien antara kelompok I dan kelompok II waktu pemasangan pin.

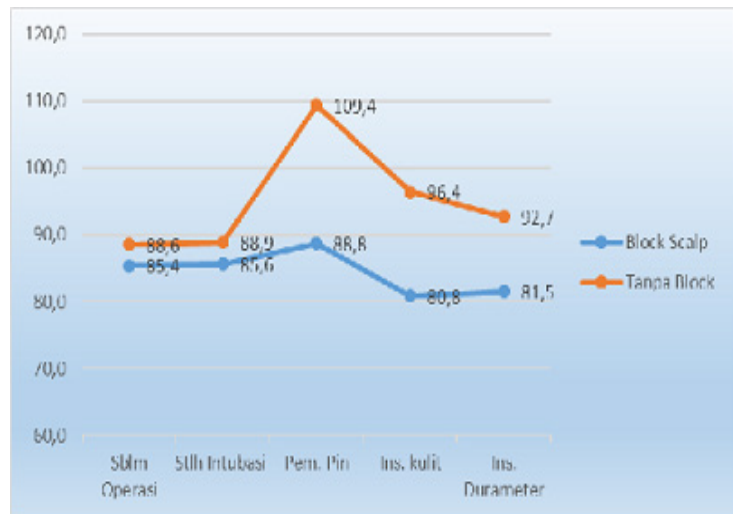

Gambar 5. Diagram Garis Perbandingan Perubahan Laju Nadi antara Kelompok Blok Scalp dengan Kelompok Tanpa Blok.

Waktu pemasangan pin pasien pada kelompok I dengan laju nadi rata-rata $88,78 \pm 9,55$ dan pada kelompok II dengan laju nadi rata-rata 109,44 $\pm 9,36$. Hasil uji statistik didapatkan nilai $\mathrm{p}=0,000$ $(p<0,05)$ yang berarti bahwa terdapat perbedaan yang signifikan laju nadi pasien antara kelompok I dan kelompok II waktu pemasangan pin.

\begin{tabular}{|c|c|c|c|}
\hline \multirow[t]{2}{*}{ Laju Nadi } & \multicolumn{2}{|c|}{ Perlakuan } & \multirow[t]{2}{*}{$\mathrm{P}$} \\
\hline & $\begin{array}{c}\text { Kelompok I } \\
\quad(n=18)\end{array}$ & $\begin{array}{c}\text { Kelompok II } \\
\quad(\mathrm{n}=18)\end{array}$ & \\
\hline Setelah Intubasi & $85,61 \pm 7,77$ & $88,94 \pm 8,13$ & $0,234^{2}$ \\
\hline Pemasangan pin & $88,78 \pm 9,55$ & $109,44 \pm 9,36$ & $0,000^{1}$ \\
\hline Insisi kulit & $80,83 \pm 4,84$ & $96,44 \pm 9,31$ & $0,000^{1}$ \\
\hline Insisi Durameter & $81,50 \pm 4,90$ & $92,72 \pm 7,98$ & $0,000^{1}$ \\
\hline
\end{tabular}

Ket : ${ }^{1}$ uji independent $t$ test $;{ }^{2}$ uji mann whitney 
Tabel 5. Perbedaan Penambahan Fentanyl antara kelompok yang diberikan terapi tambahan blok scalp (kelompok I) dengan pasien tanpa terapi tambahan blok scalp (kelompok II)

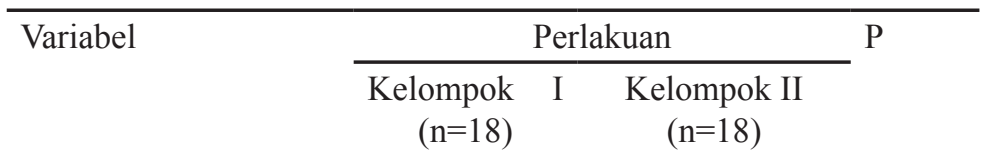

\begin{tabular}{llll}
\hline Penambahan Fentanyl & $72,22 \pm 25,57$ & $130,56 \pm 38,88$ & 0,000 \\
\hline Ket; Uji Mann Whitney & &
\end{tabular}

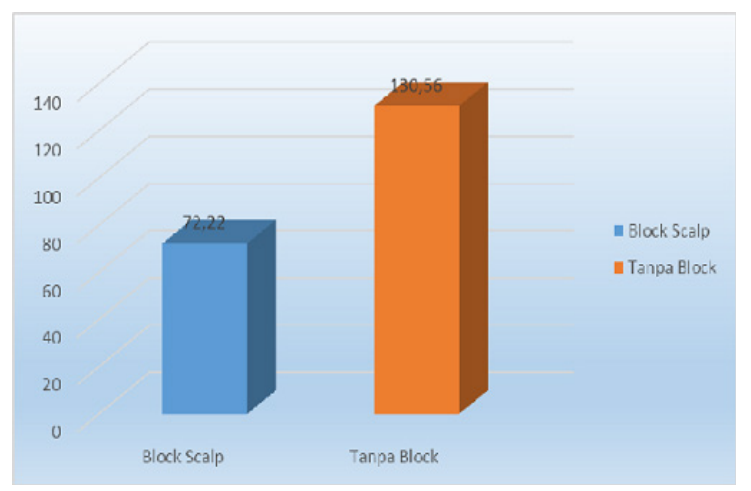

Gambar 6. Diagram Batang Perbandingan Penambahan Fentanyl antara Kelompok Blok Scalp dengan Kelompok Tanpa Blok.

Berdasarkan tabel 5 dan gambar 6, diketahui bahwa pasien pada kelompok I dengan penambahan fentanyl rata-rata $72,22 \pm 25,57$ dan pada kelompok II dengan penambahan fentanyl rata-rata 130,56 $\pm 38,88$. Hasil uji statistik didapatkan nilai $\mathrm{p}=0,000(\mathrm{p}<0,05)$ yang berarti bahwa terdapat perbedaan yang signifikan dimana pasien dengan tambahan terapi blok scalp lebih sedikit penambahan fentanylnya dibandingkan dengan tanpa blok scalp.

Tabel 6. Perbedaan efek samping antara kelompok yang diberikan terapi tambahan blok scalp (kelompok I) dengan pasien tanpa terapi tambahan blok scalp (kelompok II)

\begin{tabular}{llll}
\hline Efek Samping & \multicolumn{2}{c}{ Perlakuan } & P \\
\cline { 2 - 3 } & $\begin{array}{c}\text { Kelompok I } \\
(\mathrm{n}=18)\end{array}$ & $\begin{array}{c}\text { Kelompok II } \\
(\mathrm{n}=18)\end{array}$ & \\
\hline Hipertensi & $8(44,4 \%)$ & $17(94.4 \%)$ & 0,001 \\
Hipotensi & $0(0,0 \%)$ & $0(0,0 \%)$ & $\mathrm{N} / \mathrm{S}$ \\
Bradikardia & $0(0,0 \%)$ & $0(0,0 \%)$ & $\mathrm{N} / \mathrm{S}$ \\
Saturasi & $0(0,0 \%)$ & $0(0,0 \%)$ & $\mathrm{N} / \mathrm{S}$ \\
\hline
\end{tabular}

Ket: Uji Chi Square

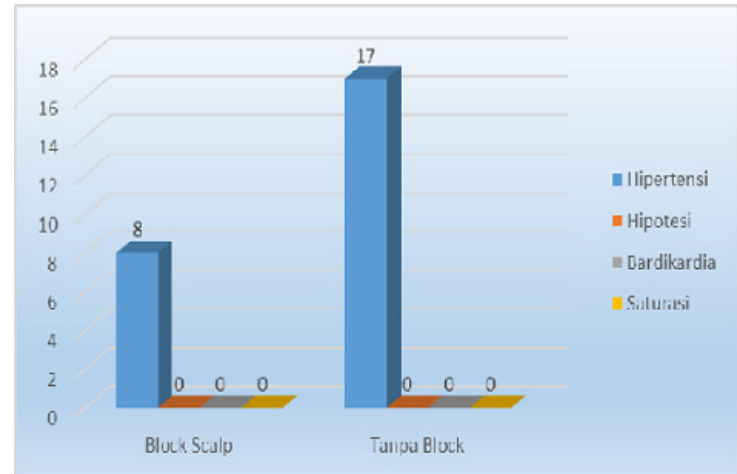

Gambar 7. Diagram Batang Perbandingan Efek Samping antara Kelompok Blok Scalp dengan Kelompok Tanpa Blok.

dimana pada kelompok I ada 8 pasien $(44,4 \%)$ dan pada kelompok II ada 17 pasien $(94,4 \%)$. Hasil uji statistik didapatkan nilai $\mathrm{p}=0,001(\mathrm{p}<0,05)$ yang berarti bahwa terdapat perbedaan yang signifikan kejadian hipertensi antara pasien kelompok I dan kelompok II, dimana pasien dengan tambahan terapi blok scalp lebih sedikit kejadian hipertensi dibandingkan dengan tanpa blok scalp.

\section{Pembahasan}

Hasil uji statistik dari karakteristik dasar subyek penelitian didapatkan nilai $\mathrm{p}=0,158 \quad(\mathrm{p}>0,05)$ yang berarti bahwa tidak terdapat perbedaan yang signifikan karakteristik pasien antara kelompok I dan kelompok II berdasarkan usia, atau dapat dikatakan usia dari kedua kelompok tersebut homogen yang artinya kelompok I dan II layak untuk dibandingkan. Hasil penelitian ini menunjukkan bahwa pemberian penambahan blok scalp levobupivakain mampu menurunkan respon hemodinamik seperti tekanan darah, MAP dan laju nadi, dan juga memberikan penambahan fentanyl yang lebih sedikit dibandingkan dengan 
tanpa blok scalp. Pada prosedur elektif bedah saraf, menjaga stabilitas hemodinamik dan perfusi optimal serebral adalah suatu hal yang sangat penting. Banyak stimuli yang dapat mengganggu stabilitas hemodinamik. Walaupun sudah banyak teknik anestesi yang tersedia, resiko terjadinya ketidakstabilan hemodinamik di awal prosedur bedah saraf diantaranya pada saat pemasangan pin, insisi kulit dan insisi duramater masih tinggi. Dengan menggabungkan teknik blok scalp sesaat setelah induksi anestesia umum dapat memberikan beberapa keuntungan untuk pasien. Dengan melakukan blok saraf-saraf sensoris yang menginervasi krania dapat membantu menumpulkan respon hemodinamik yang lebih baik dibandingkan hanya dengan infiltrasi daerah sekitar insisi. ${ }^{9}$

Penelitian ini dilakukan pada 36 pasien sesuai kriteria inklusi yang terbagi dua kelompok yang menjalani operasi kraniotomi eksisi tumor. Berdasarkan usia, jenis kelamin, status gizi, tingkat pendidikan didapatkan data yang homogen. Pada saat awal kraniotomi pada waktu pemasangan pin pada detak jantung, tekanan darah, mean arterial pressure menunjukkan secara signifikan lebih tinggi pada pasien tanpa blok scalp terutama pada saat pemasangan pin. Tidak dapatkan reaksi alergi, hematoma maupun pruritus pada tindakan blok scalp tersebut. Penambahan blok scalp levobupivakain memberikan tekanan darah sistolik lebih rendah dibandingkan dengan pasien tanpa blok scalp. Dimana diketahui bahwa tekanan darah sistolik pada waktu penambahan pin $(\mathrm{p}=0,003)$, menunjukkan perbedaan yang signifikan antara pasien yang diberikan blok scalp dengan pasien tanpa blok. Penambahan blok scalp levobupivakain memberikan tekanan darah diastolik lebih rendah dibandingkan dengan pasien tanpa blok scalp. Penambahan blok scalp levobupivakain memberikan MAP lebih rendah dibandingkan dengan pasien tanpa blok scalp. Dimana diketahui bahwa MAP pada waktu penambahan pin $(\mathrm{p}=0,000)$, insisi kulit $(\mathrm{p}=0,000)$, dan insisi durameter $(\mathrm{p}=0,002)$ menunjukkan perbedaan yang signifikan antara pasien yang diberikan blok scalp dengan pasien tanpa blok.

Laju nadi pada waktu penambahan $\operatorname{pin}(\mathrm{p}=0,000)$, insisi kulit $(\mathrm{p}=0,000)$, dan insisi durameter $(\mathrm{p}=0,000)$ juga menunjukan perbedaan yang signifikan antara pasien yang diberikan block scalp dengan pasien tanpa blok. Hasil uji statistik didapatkan nilai $\mathrm{p}=0,000(\mathrm{p}<0,05)$ yang berarti bahwa terdapat perbedaan respon yang signifikan terhadap kedua kelompok. Pada hasil-hasil tersebut di atas peningkatan yang paling tinggi di antara waktu stimuli yang lain adalah pada saat pemasangan pin. Ini sesuai dengan teori dimana pemasangan pin kepala merupakan salah satu bagian penting pada bedah saraf terutama pada pasien tumor otak, kepala ditopang dan dipasang pin metalik ke dalam perikranium yang dapat menyebabkan stimulasi tinggi nyeri yang dapat mempengaruhi respon hemodinamik yang cukup tinggi dibanding tindakan lain. ${ }^{4}$

Terdapat perbedaan yang signifikan penambahan fentanyl pasien antara kelompok I dan kelompok II, dimana pasien dengan tambahan terapi blok scalp lebih sedikit penambahan fentanylnya dibandingkan dengan tanpa blok scalp. Ini sejalan dengan penelitian lain yang dilakukan membandingkan antara bupivakain $0,5 \%$ dengan normal salin dimana terdapat peningkatan signifikan terutama pada saat pemasangan pin. Satu penelitian juga membuktikan bahwa bupivakain $0,25 \%$ dibandingkan dengan normal salin memberikan kontrol hemodinamik yang lebih efektif pada tahap awal kraniotomi frontotemporal. Hasil uji statistik dari kedua kelompok yang berkaitan dengan efek samping yang dapat terjadi didapatkan nilai $\mathrm{p}=0,001$ $(p<0,05)$ yang berarti bahwa terdapat perbedaan yang signifikan kejadian hipertensi antara pasien kelompok I dan kelompok II, dimana pasien dengan tambahan terapi blok scalp lebih sedikit kejadian hipertensi dibandingkan dengan tanpa blok scalp. Keterbatasan penelitian ini adalah tidak menggunakan alat pengukur kedalaman anestesi sehingga penyeragaman tingkat anestesi di antara kelompok tidak terukur secara obyektif dikarenakan alat yang terbatas dan daerah operasi pasien yang tidak memungkinkan pemasangan, tidak dilakukan pengukuran saat pengeboran tulang, distribusi jenis kelamin kurang merata serta daerah insisi kraniotomi juga tidak spesifik dinilai pada area tertentu. 